\title{
Structural and surface analysis of chemical vapor deposited boron doped aluminum nitride thin film on aluminum substrates
}

\author{
Shanmugan Subramani*, Mutharasu Devarajan \\ Nano Optoelectronics Research Laboratory, School of Physics, Universiti Sains Malaysia (USM), 11800, Minden, Pulau \\ Pinang, Malaysia
}

\begin{abstract}
Chemical vapor deposition (CVD) process was conducted for synthesis of boron (B) doped aluminum nitride (B-AlN) thin films on aluminum (Al) substrates. To prevent melting of the $\mathrm{Al}$ substrates, film deposition was carried out at $500{ }^{\circ} \mathrm{C}$ using tert-buthylamine $\left({ }^{\mathrm{t}} \mathrm{BuNH}_{2}\right)$ solution delivered through a bubbler as a nitrogen source instead of ammonia gas $\left(\mathrm{NH}_{3}\right)$. B-AlN thin films were prepared from three precursors at changing process parameters (gas mixture ratio). X-ray diffraction (XRD) technique and atomic force microscope (AFM) were used to investigate the structural and surface properties of B-AlN thin films on $\mathrm{Al}$ substrates. The prepared thin films were polycrystalline and composed of mixed phases \{cubic $\left(\begin{array}{lll}1 & 1 & 1\end{array}\right)$ and hexagonal $\left.\left(\begin{array}{lll}1 & 0 & 0\end{array}\right)\right\}$ of AlN and BN with different orientations. Intensive AlN peak of high intensity was observed for the film deposited at a flow rate of the total gas mixture of $25 \mathrm{sccm}$. As the total gas mixture flow decreased from $60 \mathrm{sccm}$ to $25 \mathrm{sccm}$, the crystallite size of AlN phase increased and the dislocation density decreased. Reduced surface roughness (10.4 nm) was detected by AFM for B-AlN thin film deposited on $\mathrm{Al}$ substrate using the lowest flow rate $(25 \mathrm{sccm})$ of the total gas mixture.
\end{abstract}

Keywords: B-AlN; thin film synthesis; CVD; Al substrate structural parameter; surface analysis

\section{Introduction}

Aluminum nitride (AIN) is a promising ceramic material from group III nitrides which has high thermal conductivity $\left(260 \mathrm{~W} \cdot \mathrm{m}^{-1} \cdot \mathrm{K}^{-1}\right)$, high mechanical strength, and excellent electrical insulation [1-3]. Due to the excellent properties of AlN, it has attracted attention in producing thin films by various methods, such as reactive sputtering [4$6]$, pulsed laser deposition $[7,8]$, reactive molecular beam deposition [9], and chemical vapor deposition (CVD) [10-12]. CVD has advantages over physical vapor deposition (PVD), such as high deposition rate, large deposition area and the fact that ultra-high vacuum condition is unnecessary, which is very advantageous for industrial mass production [13]. Ammonia gas $\left(\mathrm{NH}_{3}\right)$ is a common nitrogen source for nitride growth in CVD process to synthesize AIN, [14, 15]. However, the high thermal stability of $\mathrm{NH}_{3}$ requires high

*E-mail: subashanmugan@gmail.com synthesis temperature (typically $\geqslant 1000{ }^{\circ} \mathrm{C}$, thus high-temperature substrates to deposit high quality AlN thin films, which seriously limits the choice of substrate materials available for suitable application in modern electronics where $\mathrm{Al}$ substrates are considered as the best choice due to cost effectiveness and efficient thermal management. Moreover, $\mathrm{NH}_{3}$ is hazardous to health and requires proper exhaust system during the synthesis process.

To reduce the substrate temperature, plasmaenhanced CVD (PECVD) [16] system has been suggested by other researchers where the plasma activated reactions occur at lower temperature, however, the technique is difficult to control and expensive. To overcome this, metal-organic precursors, such as hexa(dimethylamido)dialuminum [ $\left.\mathrm{Al}_{2}\left(\mathrm{NMe}_{2}\right)_{6}\right]$ [17] and hexamethylaluminum $\left[\mathrm{Al}_{2}\left(\mathrm{CH}_{3}\right)_{6}\right]$ [18] have been developed to overcome the problem. However, the precursors are not easy to handle and not stable in the presence of oxygen and moisture. There are other reports where single-source precursor, 
such as trimethylaluminum ammonia [ $\left(\mathrm{Me}_{3} \mathrm{Al}\left(\mathrm{NH}_{3}\right)\right]$ adduct [19] has been utilized to simplify the precursor usage in CVD process. Nevertheless, the preparation of single-source precursors may involve complex and costly procedures which are not recommended for conventional CVD technique as it has very low vapor pressures ( $\ll 133 \mathrm{~Pa}$ at room temperature), which requires the heating of source and reactor lines and the use of high-vacuum CVD equipment. Moreover, this type of single source precursor needs higher temperature $\left(>900{ }^{\circ} \mathrm{C}\right)$ to produce high quality AlN thin film [20].

Alternatively, tert-buthylamine $\left({ }^{\mathrm{t}} \mathrm{BuNH}_{2}\right)$ was chosen as nitrogen source instead of $\mathrm{NH}_{3}$ due to its vapor pressure $\left(4.5 \times 10^{4} \mathrm{~Pa}\right.$ at $\left.25^{\circ} \mathrm{C}\right)$ suitable for the deposition conditions [21]. There were many reports on the successive use of ${ }^{t} \mathrm{BuNH}_{2}$ as nitrogen source at lower temperature $\left(400{ }^{\circ} \mathrm{C}\right.$ to $\left.600{ }^{\circ} \mathrm{C}\right)[22,23]$ but the deposition of AlN thin film on $\mathrm{Al}$ substrates has not been considered probably because the conventional CVD system should be modified and need a proper precursor delivery system like gas bubbler. Many elements, such as $\mathrm{Cr}$ [24], Si [25], Mg [26], Mn [27] etc., have been suggested as a dopant to AlN to modify the properties for particular electronic applications. The properties of AlN thin film, especially dielectric function, were improved by the addition of B into AlN material using sputtering process as reported in the literature [28]. Except our author group, there are no other reports on using $B$ as a dopant and synthesizing B doped AlN (B-AlN) thin films over Al substrate using CVD approach with a gas bubbler setup as a liquid precursor delivery system especially for ${ }^{\mathrm{t}} \mathrm{BuNH}_{2}$ solution. To optimize the synthesis methodology, it is mandatory to study the structural parameters and surface properties of $\mathrm{B}-\mathrm{AlN}$ thin films on $\mathrm{Al}$ substrates derived from CVD equipped with the gas bubbler setup.

In this work, B-AlN thin films were synthesized by CVD method using gas bubbler arrangement and their structural and surface properties were characterized for various flow rates of precursors using X-ray diffraction technique and atomic force microscopy (AFM). In our previous study, the same methodology was employed to deposit
B-AlN on $\mathrm{Si}$ substrates and it was reported in [29]. The obtained results are compared and discussed here.

\section{Experimental}

The arrangement of the gas bubbler system integrated with a conventional CVD system is explained schematically in Fig. 1. A fused quartz tube was chosen as a working tube for the deposition of B-AlN thin films and placed in a three zone furnace (OTF-1200X-III, MTI Corp) with independent temperature controllers. Aluminum chloride $\left(\mathrm{AlCl}_{3}\right)$ powder (anhydrous sublimed, $\geqslant 98 \%$, Sigma-Aldrich), boron trichloride $\left(\mathrm{BCl}_{3}\right)$ solution (1 M solution in hexane, Acros Organics) and ${ }^{\mathrm{t}} \mathrm{BuNH}_{2}$ solution (98\%, Aldrich Chemistry) were selected as Al source, B source and nitrogen source, respectively, for the B-AlN thin film deposition process. $8 \mathrm{~g}$ of $\mathrm{AlCl}_{3}$ powder was filled in a boat type crucible and positioned at the left zone of the furnace as shown in Fig. 1.

Well cleaned Al substrates $(25 \mathrm{~mm} \times 25 \mathrm{~mm} \times 3 \mathrm{~mm})$ were positioned at the central zone which was the deposition zone of the furnace. Initially, the air inside the fused quartz tube was evacuated by rotary vacuum pump and the tube was filled with nitrogen $\left(\mathrm{N}_{2}\right)$ gas to maintain the inert atmosphere inside. The left zone temperature was set at $400{ }^{\circ} \mathrm{C}$ and the temperature of the center and right zone was maintained at (optimum) $500{ }^{\circ} \mathrm{C}$ to prevent the $\mathrm{Al}$ substrate melting and assure effective deposition.

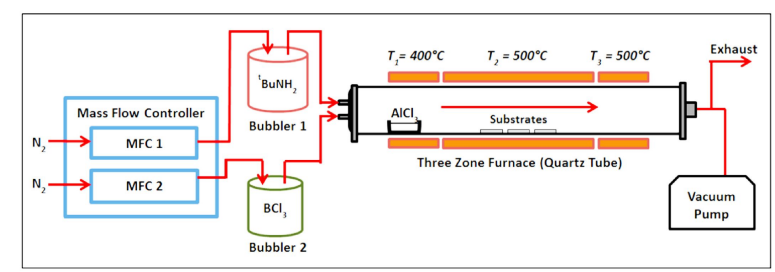

Fig. 1. Schematic diagram of CVD system for B-AlN thin film deposition.

The temperature of $400{ }^{\circ} \mathrm{C}$ was maintained at left zone to avoid the deposition during the transport of reactive mixture before reaching the center 
zone. Gas (air) bubbler was employed as the liquid precursor delivery system for ${ }^{\mathrm{t}} \mathrm{BuNH}_{2}$ solution as it is a convenient and reliable method to achieve uniform mixture of vapor with other sources of elements [30]. $\mathrm{N}_{2}$ gas was used as a carrier gas in the bubbler and its flow rate was controlled by a digital mass flow controller (MFC). The ${ }^{t} \mathrm{BuNH}_{2}$ solution was bubbled and its vapor were fed into the CVD tube at the left zone where it was mixed with $\mathrm{AlCl}_{3}$ vapor before it reached the center zone. The $\mathrm{Al}$ substrates were positioned at the center zone of the CVD tube where the mixed vapor flowed through for the deposition. $\mathrm{BCl}_{3}$ solution was bubbled with $\mathrm{N}_{2}$ carrier gas and the vapor was fed into the CVD reaction tube for about 30 minutes to enable the $\mathrm{B}$ doping process. The coating process was conducted for about one hour under atmospheric pressure. After deposition, the B-AlN thin films were subjected to annealing at $300{ }^{\circ} \mathrm{C}$ for 3 hours with $10 \mathrm{sccm}$ flow of $\mathrm{N}_{2}$ gas. Various process conditions were designed by changing the flow rates of carrier gases and source materials. In order to check the thickness of deposited film, Si substrates were placed along with $\mathrm{Al}$ substrates during the deposition process and used for thickness analysis. The thickness was measured by capturing the crosssectional image of each samples by field emission scanning electron microscope (FE-SEM) and communicated in another work from the same author group (Fig. 2) [31]. The detailed information of the process conditions used in this study was already reported in the previous work, where we used $\mathrm{Si}$ as substrates, and reproduced here for the ease of understanding (Table 1).

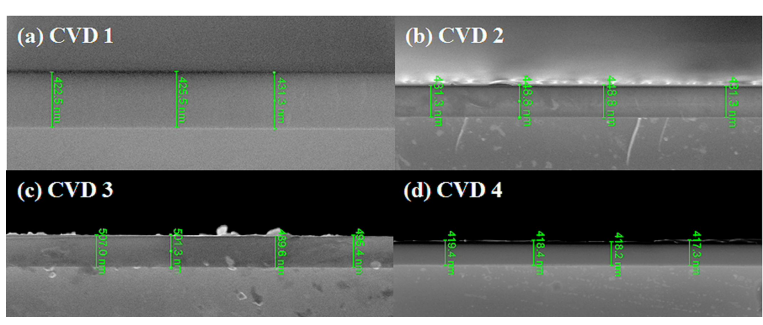

Fig. 2. FE-SEM cross-section images of thin film samples prepared at various process conditions.

The structural properties of deposited BAlN thin films were analyzed using X-ray
Table 1. Deposition parameters of B-AlN thin films obtained by CVD method.

\begin{tabular}{|c|c|c|c|}
\hline Process & \multicolumn{2}{|c|}{ Gas mixture ratio } & $\begin{array}{c}\text { Average } \\
\text { thickness } \\
{[\mathrm{nm}]}\end{array}$ \\
\hline CVD 1 & $\begin{array}{c}\mathrm{AlCl}_{3} \text { carrirer gas } \\
\left(\mathrm{N}_{2}\right) \\
\text { tert-buthylamine }\end{array}$ & \begin{tabular}{l}
\multicolumn{1}{c}{10} \\
$\mathrm{sccm}$ \\
$25 \mathrm{sccm}$
\end{tabular} & 423 \\
\hline & $\mathrm{BCl}_{3}$ & $25 \mathrm{sccm}$ & \\
\hline CVD 2 & $\begin{array}{c}\mathrm{AlCl}_{3} \text { carrirer gas } \\
\left(\mathrm{N}_{2}\right) \\
\text { tert-buthylamine } \\
\mathrm{BCl}_{3}\end{array}$ & $\begin{array}{c}5 \mathrm{sccm} \\
25 \mathrm{sccm} \\
25 \mathrm{sccm}\end{array}$ & 440 \\
\hline CVD 3 & $\begin{array}{c}\mathrm{AlCl}_{3} \text { carrirer gas } \\
\left(\mathrm{N}_{2}\right) \\
\text { tert-buthylamine } \\
\mathrm{BCl}_{3}\end{array}$ & $\begin{array}{l}2.5 \mathrm{sccm} \\
15 \mathrm{sccm} \\
15 \mathrm{sccm}\end{array}$ & 498 \\
\hline CVD 4 & $\begin{array}{c}\mathrm{AlCl}_{3} \text { carrirer gas } \\
\left(\mathrm{N}_{2}\right) \\
\text { tert-buthylamine } \\
\mathrm{BCl}_{3}\end{array}$ & $\begin{array}{l}5 \mathrm{sccm} \\
10 \\
\mathrm{sccm} \\
10 \mathrm{sccm}\end{array}$ & 418 \\
\hline
\end{tabular}

diffractometer (XRD) technique (XRD, X'PertPRO, Philips, Netherlands) and the structural parameters such as crystallite size (D), lattice parameters (a and c), dislocation density $(\delta)$, residual stress $(\sigma)$, and strain $(\epsilon)$ were calculated from the XRD pattern. A $\mathrm{CuK} \alpha(\lambda=1.54056 \AA)$ source was used, and the $2 \theta$ scanning range was selected between $20^{\circ}$ and $80^{\circ}$. The X-ray beam was operated at $40 \mathrm{kV}$ and $40 \mathrm{~mA}$ to investigate the structural properties. The surface topography was investigated with atomic force microscope (AFM) (Bruker AXS) in a tapping mode at $10 \mu \mathrm{m}$ scan range. The results obtained are compared and discussed here.

\section{Results and discussions}

\subsection{XRD analysis}

Fig. 3 shows the XRD patterns of all B-AIN thin films deposited at different process conditions (by changing the gas mixture ratio). It clearly indicates the formation of polycrystalline mixture of $\mathrm{AlN}$ and $\mathrm{BN}$ phases in all samples. It also reveals 
that the cubic (llll 111$)$ oriented AlN phases dominated the growth of the synthesized samples. Fig. 3 provides the peak intensity comparison of c-AlN ( $\left.\begin{array}{lll}1 & 1 & 1\end{array}\right)$ peaks observed for CVD 1 to CVD 4 samples. The positions of these predominant peaks are observed between $38.3^{\circ}$ and $38.6^{\circ}(2 \theta)$. Along with predominant $\left(\begin{array}{lll}1 & 1 & 1\end{array}\right)$ oriented AlN peak, two peaks with relatively low intensity related to hexagonal $\left(\begin{array}{lll}1 & 0 & 0\end{array}\right)\left\{\mathrm{h}-\left(\begin{array}{lll}1 & 0 & 0\end{array}\right)\right\}$ oriented and cubic $\left(\begin{array}{lll}1 & 1 & 1\end{array}\right)$ $\left\{c-\left(\begin{array}{lll}1 & 1 & 1\end{array}\right)\right\}$ oriented $\mathrm{BN}$ phase are also found in the XRD patterns at $2 \theta$ in the range from $40.1^{\circ}$ to $40.4^{\circ}$ and from $43.0^{\circ}$ to $43.3^{\circ}$, respectively, which is clearly shown in Fig. 4. A strong peak at $44.7^{\circ}$ is indexed to $\mathrm{Al}$ substrate and indicated in Fig. 4. The peak intensity decreases from 1322 a.u. to 864 a.u., when the flow rate of carrier gas of $\mathrm{AlCl}_{3}$ decreases from $10 \mathrm{sccm}$ to $5 \mathrm{sccm}$ (CVD 1 to CVD 2). When the total gas flow rate for CVD $2(55 \mathrm{sccm})$ is further reduced to $32.5 \mathrm{sccm}$ (CVD 3), the peak intensity of AlN slightly increases to 913 a.u. where the flow rate of ${ }^{\mathrm{t}} \mathrm{BuNH}_{2}$ and $\mathrm{BCl}_{3}$ carrier gas is further reduced compared to the flow rate conditions used in CVD 1 and CVD 2.

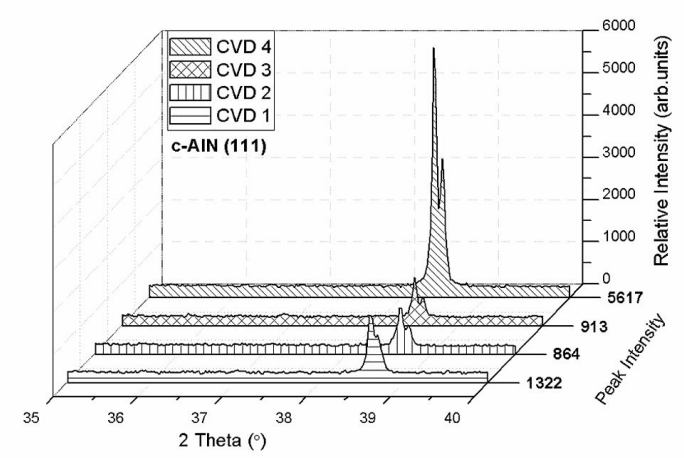

Fig. 3. XRD patterns of B-AlN coated Al substrates.

As the flow rate of ${ }^{\mathrm{t}} \mathrm{BuNH}_{2}$ and $\mathrm{BCl}_{3}$ for CVD 2 decreases from $25 \mathrm{sccm}$ to $10 \mathrm{sccm}$ (CVD 4), the intensity of $\left(\begin{array}{lll}1 & 1 & 1\end{array}\right)$ oriented AlN peak increases significantly to 5617 a.u. if the flow rate of carrier gas for $\mathrm{AlCl}_{3}$ is still maintained at the same level of $5 \mathrm{sccm}$. From the results, it can be stated that the peak intensity of AlN depends on the flow rate of ${ }^{\mathrm{t}} \mathrm{BuNH}_{2}$ and $\mathrm{AlCl}_{3}$ which are nitrogen and $\mathrm{Al}$ sources for AlN phase respectively. By reducing the total gas flow rate, the mixed vapor would have enough time to react with each other on the surface of substrate before the concentration of chemicals in the tube becomes saturated, thus more crystalline AlN can grow and higher peak is detected. Considering BN peaks, both observed h-( $\left.\begin{array}{lll}1 & 0 & 0\end{array}\right)$ and c-(llll 111$)$ peaks are of low intensity. The highest intensity value (401 a.u.) was achieved for h-( $\left.\begin{array}{lll}1 & 0 & 0\end{array}\right)$ oriented BN peak of the sample obtained in CVD 3 process where the flow rate of $\mathrm{BCl}_{3}$ was maintained at $15 \mathrm{sccm}$, while for $\mathrm{c}-\left(\begin{array}{lll}1 & 1 & 1\end{array}\right)$ oriented $\mathrm{BN}$ peak, the peak intensity was relatively small, in the range between 170 a.u. and 322 a.u., in all processes other than CVD 3. From these observations, it is concluded that the CVD 3 process conditions are suitable to grow the mixed phase of AIN and BN using CVD process with the gas bubbler setup. The lack of $\mathrm{BN}$ peak may be explained by the fact that the product was either amorphous or had smaller grain sizes [32]. The B atoms might also diffuse into AlN structure under high temperature condition during the process [33].

\subsection{Structural parameters analysis}

Based on the XRD results, the structural parameters were evaluated to study the influence of process conditions, especially carrier gas flow rate, on structural changes and properties of B-AlN thin films. The average thickness of every thin film sample was obtained from the cross-sectional image recorded from FE-SEM and the values are displayed in Table 1. It was found that the thicknesses achieved in all process conditions except for CVD 3, are very close to each other and the difference is very small (Table 1). High rate of deposition and high thickness of the deposited film was observed for CVD 3 process compared to all other 3 processes. This shows that the effect of gas flow rate on the rate of film growth is significant. The growth rate may increase by changing other parameters such as deposition temperature or pressure in the tube.

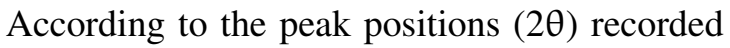
from the XRD pattern (Table 2), peak shifting from standard $2 \theta$ can be observed in all peaks as summarized in Table 2. For c-(lllll) oriented AlN peak, 


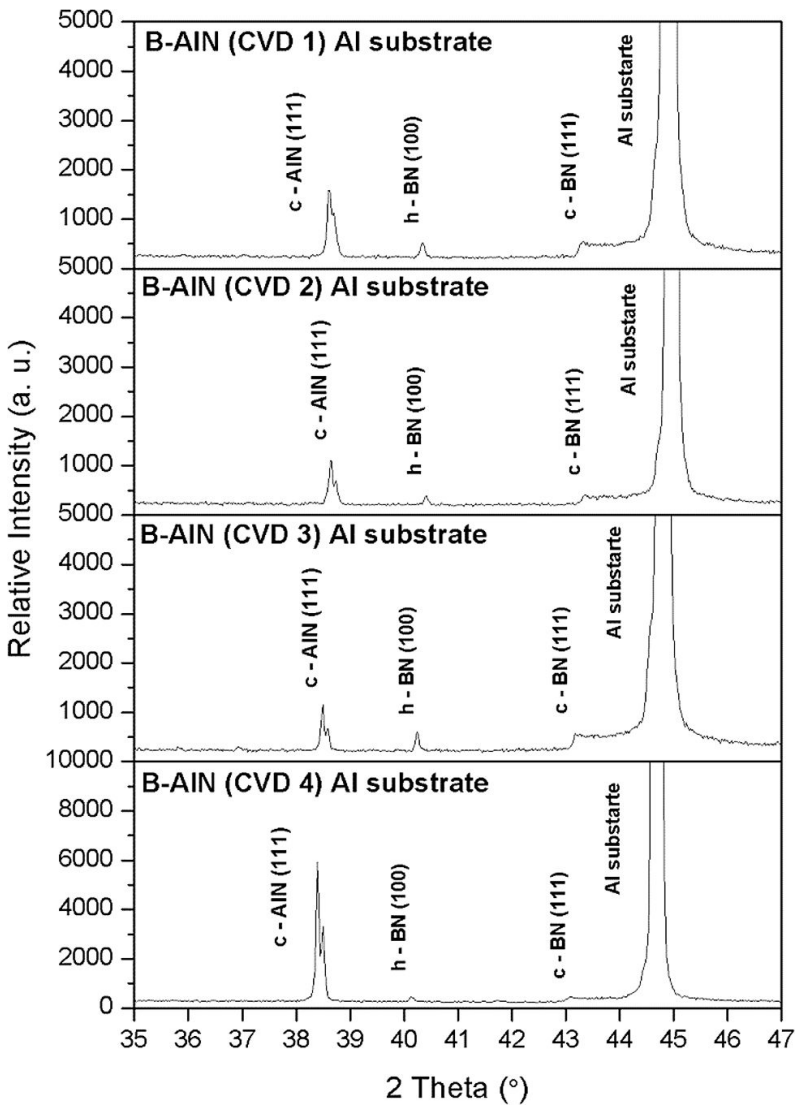

Fig. 4. Peak intensity of ( $\left.\begin{array}{lll}1 & 1 & 1\end{array}\right)$ oriented cubic AlN.

the peak shifting towards greater $2 \theta$ value occurs for the film deposited in the processes CVD 1 and CVD 2. The shifting is higher $\left(2 \theta=0.108^{\circ}\right)$ for the film deposited in CVD 2 process as compared with CVD $\left(2 \theta=0.076^{\circ}\right)$, where the total gas flow rate was reduced from $60 \mathrm{sccm}$ (CVD 1) to $55 \mathrm{sccm}$ (CVD 2). For the films deposited in CVD 3 and CVD 4 processes, the AlN peak position shifts toward lower $2 \theta$, and the degree of shifting of the peak obtained in CVD 4 is higher $\left(2 \theta=0.137^{\circ}\right)$ than in CVD $3\left(2 \theta=0.048^{\circ}\right)$. The left shifting may be connected with the $\mathrm{N}_{2}$ carrier gas flow rate of $\mathrm{AlCl}_{3}$ being $5 \mathrm{sccm}$. It reveals that the $\mathrm{Al}$ content may be reduced in this sample with respect to the nitrogen and B content. The peak shifting of AlN phase is most probably the evidence of $\mathrm{B}$ dopant that incorporates into the crystal structure during the growth process [32]. It causes greater structural defects in the film as compared with the pure AlN. Both h-BN ( $\left.\begin{array}{lll}1 & 0 & 0\end{array}\right)$ and c-BN (llll $\left.\begin{array}{lll}1 & 1 & 1\end{array}\right)$ peaks experienced also a shift towards lower $2 \theta$ value, except c-BN ( $\left.\begin{array}{lll}1 & 1 & 1\end{array}\right)$ of CVD 2 which shows minor right shifting behavior.

In Fig. 3, the peak broadening can also be observed for different process conditions. The peak broadening is correlated with the crystallite size in the B-AlN thin film. The peak broadening was estimated by measuring the full width at half maximum (FWHM) of the concerned peak from the XRD pattern. Consequently, the FWHM of all peaks was measured using the XRD software and employed to calculate the crystallite size (D) using Debye-Scherer formula [34] as given below:

$$
D=0.94 \lambda / \beta \cos \theta
$$

where $\lambda$ is wavelength (in $\AA$ ), $\beta$ is the FWHM (in radians), $\theta$ is the Bragg diffraction angle. The calculated values are given in Table 2. It clearly shows that the crystallite size is increasing with decreasing total carrier gas flow rate for all peaks. Nanocrystallites were found in c-(lllll 111$)$ oriented AlN phases obtained in CVD 1 and CVD 2 processes. Bigger crystals were observed for CVD 3 and CVD 4 samples where the flow of carrier gas of nitrogen and B source was low as compared with CVD 1 and CVD 2. In BN phase, the crystallite size is slightly bigger than the AlN crystallites size for the respective process conditions. For h-( $\left.\begin{array}{lll}1 & 0 & 0\end{array}\right)$ orientation, the crystallite size increases with a decrease in the total carrier gas flow rate up to the sample obtained in CVD 3 process. It is attributed to the effect of carrier gas flow rate from $\mathrm{AlCl}_{3}$ source. It slightly increases for CVD 4 process and hence the smaller crystallite size of $\mathrm{BN}$ phase can be observed.

During the film growth and annealing process, residual stress is developing which may cause heterogeneous plastic deformation, thermal contractions and phase transformation. The plastic deformation and thermal contractions are expected since B-AlN thin film is processed at elevated temperature. Moreover, the B doping may also cause a residual stress during the film growth. For clear understanding, the influence of doping and annealing on the change in residual stress 
Table 2. Structural properties of B-AIN thin film prepared at various CVD gas flow rates.

\begin{tabular}{|c|c|c|c|c|c|c|c|}
\hline Process & Identity & $\begin{array}{c}\text { Observed } \\
2 \theta\left[{ }^{\circ}\right]\end{array}$ & Standard $2 \theta\left[^{\circ}\right]$ & FWHM [ $\left.{ }^{\circ}\right]$ & Crystallite size [nm] & Lattice constant $[\AA]$ & Reference No. \\
\hline \multirow{3}{*}{ CVD 1} & c-AlN (llll $\left.1 \begin{array}{lll}1 & 1 & 1\end{array}\right)$ & 38.607 & 38.531 & 0.157 & 53.769 & \multirow{3}{*}{$\begin{array}{c}4.036 \\
\mathrm{a}=2.234 \\
\mathrm{c}=3.648 \\
3.617\end{array}$} & $00-046-1200$ \\
\hline & h-BN $\left(\begin{array}{lll}1 & 0 & 0\end{array}\right)$ & 40.345 & 40.828 & 0.092 & 91.666 & & 00-049-1327 \\
\hline & c-BN $\left(\begin{array}{lll}1 & 1 & 1\end{array}\right)$ & 43.297 & 43.298 & 0.120 & 71.204 & & $00-025-1033$ \\
\hline \multirow{3}{*}{ CVD 2} & c-AlN (l $\left.\begin{array}{lll}1 & 1 & 1\end{array}\right)$ & 38.639 & 38.531 & 0.085 & 99.359 & \multirow{3}{*}{$\begin{array}{c}4.033 \\
\mathrm{a}=2.231 \\
\mathrm{c}=3.643 \\
3.613\end{array}$} & $00-046-1200$ \\
\hline & h-BN $\left(\begin{array}{lll}1 & 0 & 0\end{array}\right)$ & 40.403 & 40.828 & 0.079 & 106.311 & & 00-049-1327 \\
\hline & $\mathrm{c}-\mathrm{BN}\left(\begin{array}{lll}1 & 1 & 1\end{array}\right)$ & 43.346 & 43.298 & 0.096 & 89.020 & & $00-025-1033$ \\
\hline \multirow{3}{*}{ CVD 3} & c-AlN (l $\left(\begin{array}{lll}1 & 1 & 1\end{array}\right)$ & 38.483 & 38.531 & 0.062 & 136.553 & \multirow{3}{*}{$\begin{array}{c}4.049 \\
\mathrm{a}=2.239 \\
\mathrm{~b}=3.656 \\
3.626\end{array}$} & $00-046-1200$ \\
\hline & h-BN $\left(\begin{array}{lll}1 & 0 & 0\end{array}\right)$ & 40.246 & 40.828 & 0.074 & 113.684 & & 00-049-1327 \\
\hline & $\mathrm{c}-\mathrm{BN}\left(\begin{array}{lll}1 & 1 & 1\end{array}\right)$ & 43.175 & 43.298 & 0.096 & 88.967 & & 00-025-1033 \\
\hline \multirow{3}{*}{ CVD 4} & c-AlN (lllll) & 38.394 & 38.531 & 0.057 & 148.884 & \multirow{3}{*}{$\begin{array}{c}4.058 \\
\mathrm{a}=2.245 \\
\mathrm{~b}=3.666 \\
3.634\end{array}$} & $00-046-1200$ \\
\hline & h-BN $\left(\begin{array}{lll}1 & 0 & 0\end{array}\right)$ & 40.138 & 40.828 & 0.100 & 84.552 & & $00-049-1327$ \\
\hline & c-BN ( $\left(\begin{array}{lll}1 & 1 & 1\end{array}\right)$ & 43.075 & 43.298 & 0.096 & 88.937 & & $00-025-1033$ \\
\hline
\end{tabular}

of B-AlN thin film has been considered. Consequently, the internal stress $(\sigma)$ developed in the deposited film is calculated using the following relation:

$$
\sigma=-E\left(d_{a}-d_{o}\right) /\left(2 d_{o} Y\right)
$$

where $d_{o}$ and $d_{a}$ are the $d$ spacing of bulk and thin film forms, respectively [35]. The Young modulus (E) and Poisson ratio (Y) of $\mathrm{AlN}$ and $\mathrm{BN}$ are $\mathrm{E}_{\mathrm{AlN}}=308 \mathrm{GPa}$ [36], $\mathrm{E}_{\mathrm{BN}}=748 \mathrm{GPa}$ [37], $\mathrm{Y}_{\mathrm{AlN}}=0.29$ [38], and $\mathrm{Y}_{\mathrm{BN}}=0.19$ [39], respectively. The stress exerted on the film can be identified by the sign of the calculated value. Positive sign represents compressive stress whereas negative sign denotes tensile stress. With the reference to $2 \theta$ from Table 2, the peaks shifted to higher angle mean that the film experienced tensile stress whereas the peaks shifted to lower $2 \theta$ angle refer to compressive stress during the film growth. As far as AlN phase is concerned, the stress developed during the film growth in CVD 1 and CVD 2 process conditions is tensile in nature and it is increasing with carrier gas flow rate of $\mathrm{AlCl}_{3}$.

A conversion from tensile to compressive was noticed in CVD 3 and CVD 4 process conditions where the total carrier gas flow rate was reduced. It is noticed from Table 3 that the observed stress values are very low when compared with the value for $\mathrm{BN}$ phase in the prepared B-AlN thin film. For h-( $\left.\begin{array}{lll}1 & 0 & 0\end{array}\right)$ oriented BN phase, the stress value increases with the total carrier gas flow rate decrease. The stress conversion from compressive to tensile is observed for c-(lllll 1110 AlN phase along with a conversion from tensile to compressive stress for c-(llll 111$) \mathrm{BN}$ phase. c-(111) BN phase shows higher value of compressive stress than the value of c-(lll 111$)$ AlN phase. Dislocation density $(\delta)$ is a measure of defects resulting from the crystallite size change during the growth of films as well as post deposition process. Since several factors influence the CVD process, it has to be addressed and evaluated by the relation [40]:

$$
\delta=1 / D^{2}
$$

The obtained values are summarized in Table 3 . From Table 3 , it is seen that the $\delta$ values for c-( $\left.\begin{array}{lll}1 & 1 & 1\end{array}\right)$ oriented AlN phase decrease with the total carrier gas flow rate decrease. Considering BN phases (both cubic and hexagonal), the $\delta$ value decreases for the film processed at reduced carrier gas flow rate of $\mathrm{AlCl}_{3}$ until the flow conditions set at CVD 3 and a small increase in $\delta$ value is noticed in case of CVD 4 , where the $\mathrm{AlCl}_{3}$ carrier gas flow rate has slightly increased. High $\left(3.46 \times 10^{14}\right.$ lines $\left./ \mathrm{m}^{2}\right)$ and low $\left(4.51 \times 10^{13}\right.$ lines $\left./ \mathrm{m}^{2}\right)$ values of $\delta$ are noticed 
for c-(l 11 1 $)$ AlN phase for CVD 1 and CVD 4 process conditions, respectively. As particle size changes, the micro strain inside the lattice may also change. The microstrain $(\epsilon)$ developed in the synthesized films has been calculated using the relation [41]:

$$
\varepsilon=\beta \cot \theta / 4
$$

The results are summarized in Table 3. It is noticed that the changes in the microstrain are following the same trend as it is observed for dislocation density. Thus, the high $\left(1.95 \times 10^{-3}\right)$ and low $\left(7.08 \times 10^{-4}\right)$ values of $\epsilon$ are noticed for c-( $\left(\begin{array}{lll}1 & 1 & 1\end{array}\right)$ AlN phase developing in CVD 1 and CVD 4 process conditions, respectively.

\subsection{Surface analysis}

A comparison of surface morphologies of a bare Al substrate and B-AlN thin film coated Al substrates is presented in Fig. 5. The images show that the surface is composed of drop-like randomly oriented nanosized grain structure. The root mean square (RMS) surface roughness and particle size have been analyzed from the images using the nanoscope software and are recorded in Table 4.

It is found that the surface roughness of bare $\mathrm{Al}$ substrate is reduced by B-AlN film coating for the films deposited in all process conditions except for CVD 3 process. The surface has relatively high roughness of $30.8 \mathrm{~nm}$ as compared with those of other substrates. It is clearly seen in Fig. 5d which shows very large grains on the surface of the BAlN thin films. The average particle size of CVD 3 is also large $(1068 \mathrm{~nm})$, and it can be noticed from Fig. $5 \mathrm{~d}$ that the drop-like particles are larger than the other ones.

It shows that reduced $\mathrm{N}_{2}$ carrier gas flow rate $(2.5 \mathrm{sccm})$ does not result in reduction of surface roughness and particle size. In case of CVD 2 and CVD 4, the flow rate of $\mathrm{N}_{2}$ carrier gas of $5 \mathrm{sccm}$ promotes the growth of thin films with lower roughness and particle size as compared with $10 \mathrm{sccm}$ used in CVD 1. When the flow rate of tert-buthylamine and $\mathrm{BCl}_{3}$ are further reduced from $25 \mathrm{sccm}$ (CVD 2) to $10 \mathrm{sccm}$ (CVD 4), the surface roughness can be further reduced from $10.4 \mathrm{~nm}$

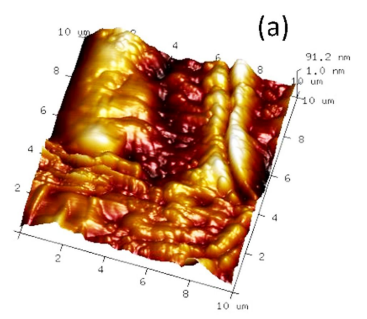

(b)
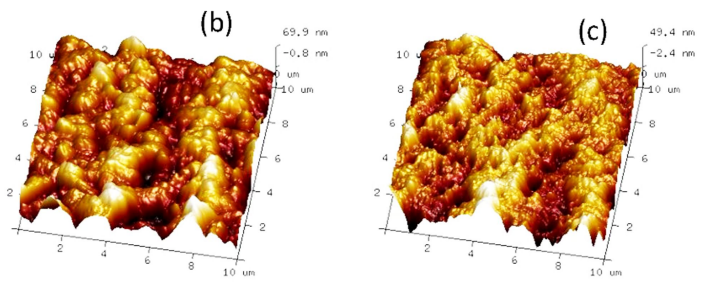

(d)

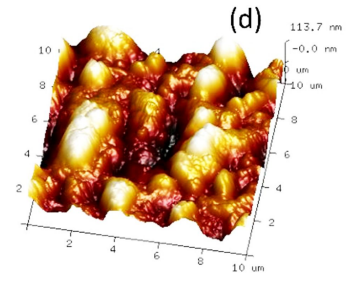

(e)

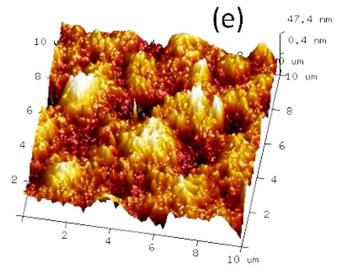

Fig. 5. AFM surface images of bare $\mathrm{Al}$ (a) and B-AlN thin films on Al using (b) CVD 1, (c) CVD 2, (d) CVD 3, (e) CVD 4 process conditions.

to $9.18 \mathrm{~nm}$, but in contrast, the particle size slightly increases from $436 \mathrm{~nm}$ to $601 \mathrm{~nm}$ and it is clearly seen in Fig. 5e that more grains are formed as compared to Fig. 5c.

\section{Conclusions}

In this work, B-AlN films were successfully deposited on $\mathrm{Al}$ substrates at $500{ }^{\circ} \mathrm{C}$ by $\mathrm{CVD}$ method using ${ }^{t} \mathrm{BuNH}_{2}$ as nitrogen source with a gas bubbler setup. The synthesized films were polycrystalline with mixed phases and predominant c-(llll 111$)$ AlN peak with high intensity. BN peaks were also identified and influenced by the growth of c-(lllll 11 AlN on Al substrates. The peak shifting caused by B doping of AlN crystal lattice was observed. The structural studies revealed the formation of AlN with low residual stress and reduced defects. Over all, the crystalline quality was improved for decreased total gas mixture ratio. From AFM analysis, the improved surface 
Table 3. Internal stress $(\sigma)$, dislocation density $(\delta)$ and strain $(\epsilon)$ of B-AlN thin film in all deposition conditions.

\begin{tabular}{|c|c|c|c|c|}
\hline Process & Identity & $\begin{array}{c}\text { Internal } \\
\text { stress, } \\
\sigma \\
{[\mathrm{GPa}]}\end{array}$ & $\begin{array}{c}\text { Dislocation } \\
\text { density, } \delta \\
{\left[\text { lines } / \mathrm{m}^{2}\right]}\end{array}$ & Strain, $\epsilon$ \\
\hline \multirow{3}{*}{ CVD 1} & c-AlN (llll $\left.\begin{array}{lll}1 & 1 & 1\end{array}\right)$ & -1.01 & $3.46 \times 10^{14}$ & $1.95 \times 10^{-3}$ \\
\hline & h-BN ( $\left.\begin{array}{lll}1 & 0 & 0\end{array}\right)$ & 22.34 & $1.19 \times 10^{14}$ & $1.10 \times 10^{-3}$ \\
\hline & $\mathrm{c}-\mathrm{BN}\left(\begin{array}{lll}1 & 1 & 1\end{array}\right)$ & 0.03 & $1.97 \times 10^{14}$ & $1.32 \times 10^{-3}$ \\
\hline \multirow{3}{*}{ CVD 2} & $\mathrm{c}-\mathrm{AlN}\left(\begin{array}{lll}1 & 1 & 1\end{array}\right)$ & -1.44 & $1.01 \times 10^{14}$ & $1.05 \times 10^{-3}$ \\
\hline & h-BN ( $\left(\begin{array}{lll}1 & 0 & 0\end{array}\right)$ & 19.64 & $8.85 \times 10^{13}$ & $9.44 \times 10^{-4}$ \\
\hline & c-BN (l $\left.\begin{array}{lll}1 & 1 & 1\end{array}\right)$ & -2.10 & $1.26 \times 10^{14}$ & $1.05 \times 10^{-3}$ \\
\hline \multirow{3}{*}{ CVD 3} & c-AlN (llll $\left.\begin{array}{lll}1 & 1 & 1\end{array}\right)$ & 0.65 & $5.36 \times 10^{13}$ & $7.70 \times 10^{-4}$ \\
\hline & h-BN ( $\left(\begin{array}{lll}1 & 0 & 0\end{array}\right)$ & 26.93 & $7.74 \times 10^{13}$ & $8.86 \times 10^{-4}$ \\
\hline & c-BN $\left(\begin{array}{lll}1 & 1 & 1\end{array}\right)$ & 5.30 & $1.26 \times 10^{14}$ & $1.06 \times 10^{-3}$ \\
\hline \multirow{3}{*}{ CVD 4} & $\mathrm{c}$-AlN $\left(\begin{array}{lll}1 & 1 & 1\end{array}\right)$ & 1.84 & $4.51 \times 10^{13}$ & $7.08 \times 10^{-4}$ \\
\hline & h-BN ( $\left(\begin{array}{lll}1 & 0 & 0\end{array}\right)$ & 31.90 & $1.40 \times 10^{14}$ & $1.19 \times 10^{-3}$ \\
\hline & c-BN (l $\left.\begin{array}{lll}1 & 1 & 1\end{array}\right)$ & 9.64 & $1.26 \times 10^{14}$ & $1.06 \times 10^{-3}$ \\
\hline
\end{tabular}

Table 4. Surface roughness and particle size evaluated by AFM software analysis.

\begin{tabular}{ccc}
\hline Sample & Roughness (Ra) [nm] & $\begin{array}{c}\text { Particle size } \\
{[\mathrm{nm}]}\end{array}$ \\
\hline \hline Bare Al & 19.6 & 697 \\
CVD 1 & 14.8 & 732 \\
CVD 2 & 10.4 & 436 \\
CVD 3 & 30.8 & 1068 \\
CVD 4 & 9.2 & 601 \\
\hline
\end{tabular}

properties were also observed for the film grown at the low total gas mixture ratio in CVD 4 process

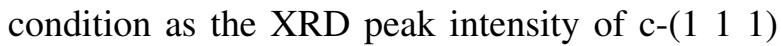
oriented AlN phase was the highest among all the films obtained at the four deposition parameters. From the obtained results, it is concluded that the cubic phase AlN could be deposited on Al substrates by using CVD process. The obtained structures can be used for heat dissipation in electronic devices for efficient thermal management.

\section{References}

[1] FEng Z.C., III-Nitride Semiconductor Materials, World Scientific, Taiwan, 2006.

[2] Chaudhuri J., Nyakiti L., Lee R.G., Gu Z., Edgar J.H., Wen J.G., Mater. Charact., 58 (2007), 672.
[3] Olivares J., GonzÁlez-Castilla S., Clement M., SAnZ-Hervás A., Vergara L., SAngrador J., Iborra E., Diam. Relat. Mater, 16 (2007), 1421.

[4] Kar J.P., Bose G., Tuli S., Scripta Mater., 54 (2006), 1755.

[5] Zhang J.X., Cheng H., Chen Y.Z., Uddin A., YuAn S., Geng S.J., Zhang S., Surf. Coat. Tech., 198 (2005), 68.

[6] Xu X.H., Wu H.S., Zhang C.J., JIn Z.H., Thin Solid Films, 388 (2001), 62.

[7] Vispute R.D., Narayan J., Wu H., JagannadHAM K., J. Appl. Phys., 77 (1995), 431.

[8] Vispute R.D., Wu H., Narayan J., Appl. Phys. Lett., 67 (1995), 1549.

[9] LU H., Schaff WI. J., Hwang J., Wu H., KoLey G., Eastman L.F., Appl. Phys. Lett., 79 (2001), 1489.

[10] Guerrero R.M., Garcia J.R.V., Superficie y Vacio, 9 (2001), 82.

[11] Morita M., Uesugi N., Isogai S., Tsubouchi K., Mikoshiba N., Jpn. J. Appl. Phys., 20 (1981), 17.

[12] Chubachi Y., Sato KI., Kojima K., Thin Solid Films, 122 (1984), 259.

[13] Andrew R.B., OpenStax CNX., July 14 (2009).

[14] Roman Y.G., AdriaAnsen A.P.M., Thin Solid Films, 169 (1989), 241.

[15] Egashira Y., Kim H.J., Komiyama H., J. Am. Ceram. Soc., 77 (1994), 2009.

[16] Harris H., Biswas N., Temkin H., Gangopadhyay S., Strathman M., J. Appl. Phys., 90 (2001), 5825.

[17] Azema N., Durand J., Berjoan R., Dupuy C., Cot L., J. Eur. Ceram. Soc., 8 (1991), 291. 
[18] Gordon R.G., Hoffman D.M., Riaz U., J. Mater. Res., 6 (1991), 5.

[19] Dupuie J.L., Gulari E., J. Vac. Sci. Technol. A, 10 (1992), 18.

[20] Jones A.C., Rushworth S.A., Houlton D.J., Roberts J.S., Roberts V., Whitehouse C.R., CRitchlow G.W., Chem. Vapor Deposit, 2 (1996), 5.

[21] Roberts V., Roberts J.S., Jones A.C., RushWORTH S., In MRS online proceedings, Cambridge University Press, London, 1995, p. 395.

[22] Rushworth S.A., Brown J.R., HOUlton D.J., Jones A.C., Roberts V., Roberts J.S., Critchlow G.W., Adv. Mater. Opt. Elec., 6 (1996), 119.

[23] Jones A.C., Auld J., Rushworth S.A., Houlton D.J., CRitchlow G.W., J. Mater. Chem., 4 (1996), 1591.

[24] Wistrela E., Bittner A., Schneider M., ReissNer M., Schmid U., J. Appl. Phys., 121 (2017), 115302.

[25] PAN D., Jian J. K., Sun Y. F., Wu R., J. Alloy. Compd., 519 (2012), 41.

[26] Xiong J., Guo P., Guo F., Sun X., Gu H., Mater. Lett., 117 (2014), 276.

[27] Endo Y., Sato T., Kawamura Y., Yamamoto M., Mater. Trans., 48, (2007), 465.

[28] Felmetsger V.V., Mikhov M.K., 2011 IEEE Int. Ultrasonics Sympos. Proc., (2011) 835.

[29] Molina S.I., Sanchez A.M., Pacheco F.J., GarCIA R., SÁnchez-Garcia M.A., SANChez F.J., Calleja E., Appl. Phys. Lett., 74 (1999), 3362.
[30] Ong Z.Y., Shanmugan S., Mutharasu D., IJETT, 17 (4), (2014), 192.

[31] PIERSON H.O., Handbook of chemical vapor deposition: principles, technology and applications, William Andrew Publishing, New York, 1999.

[32] Song J.H., HuAng J.L., Lu H.H., Sung J.C., Thin Solid Films, 516 (2007), 223.

[33] Witthaut M., Cremer R., Reichert K., Neuschütz D., Thin Solid Films, 377 (2000), 478.

[34] Gordillo G., Flrez J.M., Hernandez L.C., Sol. Energ. Mat. Sol. C., 37 (1995), 273.

[35] Perry A.J., J. Vac. Sci. Tech. A, 8 (1990), 1351.

[36] Gerlich D., Dole S.L., Slack G.A., J. Phys. Chem. Solids, 47 (1986), 437.

[37] http://www. ioffe.ru/SVA/NSM/Semicond/BN/ mechanic.html, accessed on: 08.13.2014.

[38] Thokala R., Chaudhuri J., Thin Solid Films, 266 (1995), 189.

[39] Stokes A.R., Wilson A.C.J., Proc. Phys. Soc., 56 (1944), 174.

[40] Pal U., Samanta D., Ghoral S., Samantaray B.K., Chaudhuri A.K., J. Phys. D: Appl. Phys., 25 (1992), 1488.

[41] Cullity B.D., Elements of X-ray Diffraction, $2^{\text {nd }}$ ed., Addition-Wesley, London, 1978.

Received 2018-04-19 Accepted 2019-04-23 